\title{
Çocuk suprakondiler femur kırıklarına tedavi yaklaşımı
}

\author{
Adem Şahin ${ }^{1}$, Avşar Özkut ${ }^{2}$, Engin Eceviz ${ }^{3}$, Esat Uygur²
}

\begin{abstract}
ÖZET:
Çocuk suprakondiler femur kırıklarına tedavi yaklaşımı

Çocuk suprakondiler femur kırıkları yaygın olarak görülmemektedir ve literatürde bu konu ile ilgili az sayıda yayın mevcuttur. 1990-2010 yılları arasında retrospektif olarak incelenen 279 çocuk femur kırığı olgusunun 16 'sında $(\% 5,7)$ suprakondiler femur kırığı tespit edilmiştir. Femur kırığı tespit edilen bu 16 hastanın üçünde predispozan muskuloskletal hastalıklar tespit edildi [osteogenesis imperfecta (2), serebral palsi (1)]. Nondeplase kırığı olan altı hastaya direkt alçılama, dört hastaya üç hafta traksiyonu takiben anestezi altında pelvipedal alçılama ve altı hastaya da perkütan çapraz $\mathrm{K}$ teli ile tespit ve uzun bacak alçılama yapıldı. Hiçbir hastada kaynamama ve enfeksiyon görülmedi. Ameliyat sonrası takiplerde iki hastada topallama şikayeti tespit edildi. Bu hastalardan birinde serebral palsi ile beraber aynı tarafta yüksekte kalça çıkığı vardı. Eklem hareket açıklıkları serebral palsili hastada $30^{\circ}$, diğer hastada $10^{\circ}$ ekstansiyon kaybı dışında kalan 14 hastada tam olarak tespit edildi.

Anahtar kelimeler: Çocuk, suprakondiler femur, perkütan pinleme
\end{abstract}

\section{ABSTRACT:}

A treatment approach to pediatric supracondylar femur fracture

Pediatric supracondylar femur fractures are uncommon and only few publications regarding this subject are available in the current literature. Between 1990 and 2009, 279 pediatric femur fractures were retrospectively analyzed and 16 (5.7\%) supracondylar femur fractures were detected. Predisposing musculoskeletal diseases were determined in three of these 16 patients [(osteogenesis imperfecta (2), cerebral palsy (1)]. Six patients who had non-displaced fracture were performed direct casting; after 3 weeks following traction under anesthesia, four patients underwent pelvipedal cast treatment. Percutaneous crossed K-wire fixation and a long-leg cast was applied in six patients. Fusion related problem and infection were not observed in any of the patients. During the postoperative follow-up, claudication was detected in two patients. One of them with cerebral palsy had concomitant high hip dislocation on the same side. Range of motion was normal in all except two patients who had claudication. Of these, one with $30^{\circ}$ and the other with $10^{\circ}$ extension loss were observed.

Key words: Pediatric, supracondylar femur, percutaneous pinning

Ş.E.E.A.H. Tıp Bülteni 2013;47(2):55-58
'Çorlu Devlet Hastanesi, Tekirdağ-Türkiye ${ }^{2}$ Medeniyet Üniversitesi, İstanbul-Türkiye ${ }^{3}$ Lütfi Kırdar Kartal Eğitim ve Araştırma Hastanesi, İstanbul-Türkiye

Yazışma Adresi / Address reprint requests to: Dr. Adem Şahin, Çorlu Devlet Hastanesi, Tekirdağ-Türkiye

Telefon / Phone: +90-532-584-3100

E-posta / E-mail:

ademtito@yahoo.com

Geliş tarihi / Date of receipt:

3 Eylül 2012 / September 3, 2012

Kabul tarihi / Date of acceptance: 6 Eylül 2012 / September 6, 2012

\section{Giriş}

Pediatrik suprakondiler femur kırıkları ile az sayıda yayın vardır (1-3). Smith ve ark. 102 femur kırığı olan hastaları incelediklerinde, 12 (\%12) suprakondiler femur kırığı bildirmesine rağmen (4); Christopher ve ark. femur kırığı olan 200 hastanın sadece 2 'sinde suprakondiler femur kırı̆̆ı bildirmişlerdir (\%1) (5). 1990-2009 yılları arasında Göztepe Eğitim Araştırma Hastanesinde yatırılarak tedavi edilen 279 pediatrik (0-17 yaş) femur kırığından $16^{\prime}$ sı $(\% 5,7)$ suprakondiler femur kırığı olarak tespit edilmiştir. Diğer kırıkların bölgelerine göre dağılımı ise 4 intertrokanterik $(\% 1,4), 8$ subtrokanterik $(\% 2,9), 13$ kollum $(\% 4,7), 6(\% 2,2)$ distal femur (kondil, epikondil, epifiz), $232(\% 83,1)^{\prime}$ sinde diafiz kırı̆̆ı şeklindedir.

Kırık genellikle yüksek enerjili travmalar sonucu oluşur. Christoper ve ark. suprakondiler femur kırıklarını dirsek kırıkları gibi fleksiyon-ekstansiyon tipi olarak ayırmışlardır (5).

Yüksek enerjili travmalar sonucu genellikle deplase kırık oluşurken, gastroknemius ve patellar tendon 
Tablo 1: Çocuk femur kırıklarının lokalizasyonuna göre dağılımı

\begin{tabular}{lc}
\hline Kırık lokalizasyonu & sayı (\%) \\
\hline Boyun & $13(\% 4,7)$ \\
Intertrokanterik & $4(\% 1,4)$ \\
subtrokanterik & $8(\% 2,9)$ \\
Diafiz & $232(\% 83,1)$ \\
Suprakondiler & $16(\% 5,7)$ \\
Distal femur & $6(\% 2,2)$ \\
(kondil,epikondil,epifiz) &
\end{tabular}
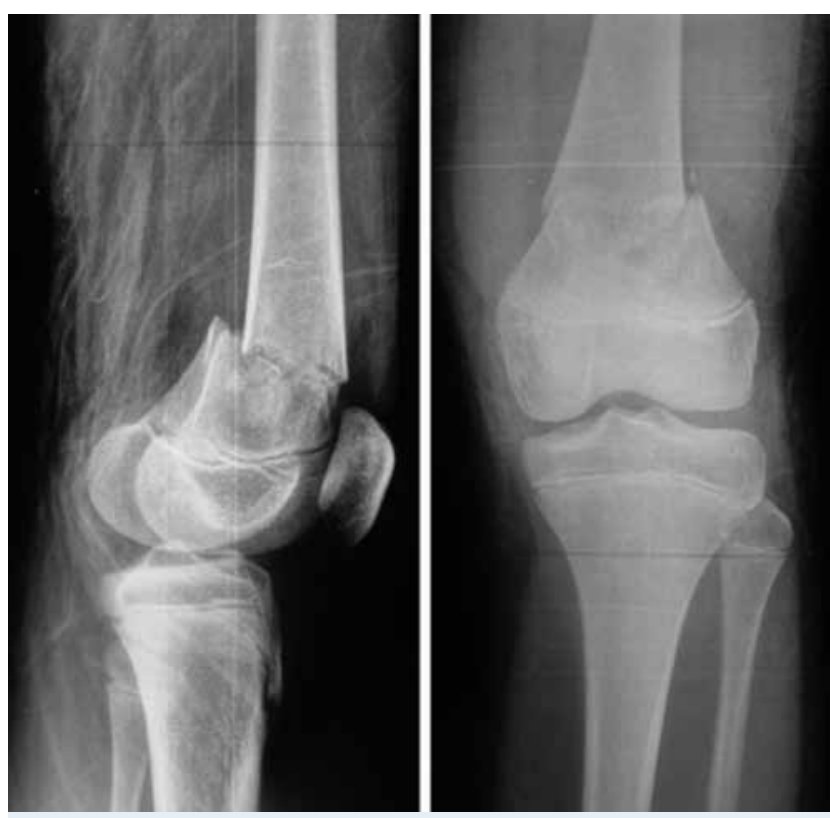

Resim 1: Suprakondiler femur kırığı
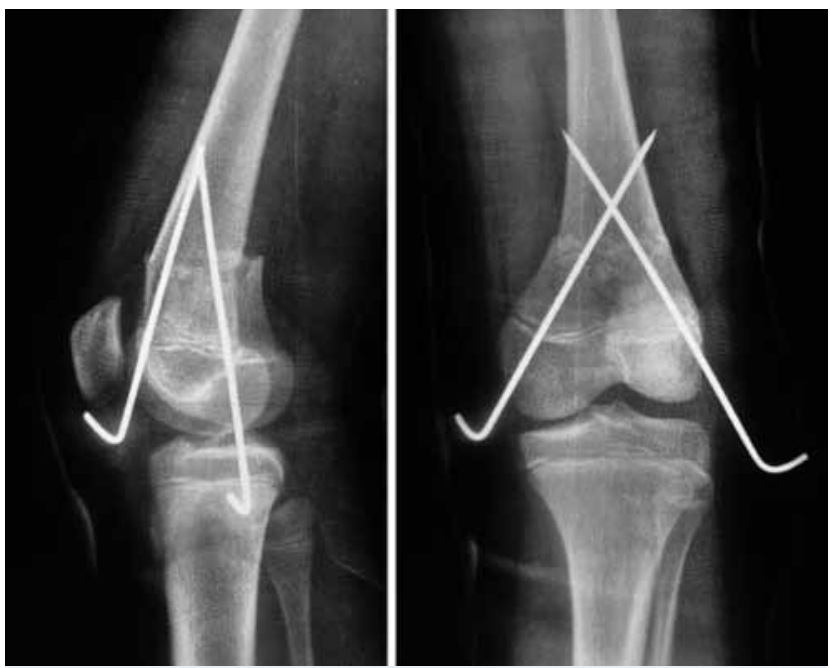

Resim 2: Çapraz K telleri ile fiksasyon çekmesine bağlı genellikle fleksiyon tipi deplase kırık oluşur. Ekstansiyon tipi kırıklar diz tam ekstansiyonda iken aksiyel yüklenmeler sonucu oluşur.

Smith ve ark. kırık oluş mekanizmasına göre displazi-nondeplase (normal-anormal kemik) olarak gruplandırma yapmışlardır. Muskuloskletal hastalıklardan dolayı düşük enerjili travmalar sonucu kırık olabileceğini söylemişlerdir (4).

Tedavi yöntemleri olarak genellikle nondeplase kırıklarda direkt alçılama, deplase kırıklarda traksiyon sonrası alçılama, pinleme+alçılama, eksternal fiksatör ve plak-vida ile tespit kullanılır. Biz bu çalışmada çocuk yaş grubu hastalarda suprakondiler femur kırıklarına tedavi yaklaşımını değerlendirmeyi amaçladık.

\section{GEREÇ ve YÖNTEM}

1990-2009 yılları arasında acil polikliniğimize başvuran 16 pediatrik hasta çalışmaya alındı. Hastaların 8'i kız, 8'i erkek ve yaş ortalaması 8,1 (4-13) yıl idi. Bu hastaların demgrafik özellikleri, kırık yerleşim yerleri, kırık etiyolojileri, tedavi yaklaşımları ve sonuçlar değerlendirildi.

\section{BULGULAR}

Hastaların kırık lokasyonları Tablo 1'de özetlenmiştir. Oniki hastada fleksiyon tipi dört hastada ekstansiyon tipi kırık mevcut idi. Hastaların 4'ü yüksek, 12 'sinde düşük enerjili travma sonucu kırık meydana geldi. Düşük enerjili travma sonucu oluşanların 2'sinde osteogenesis imperfekta, 1'inde serebral palsi mevcut idi. Osteogenesis imperfekta olan hastalarda kırık düşme, serebral palsi olan hastada fizik tedavi uygulaması sırasında kırık meydana geldi. Diğer kırık etiyolojileri Tablo 2. de detaylıca gösterilmiştir. Nondeplase kırığı olan altı hastaya direkt alçılama, dört hastaya 3 hafta traksiyonu takiben anestezi altında pelvipedal alçılama yapıldı. Altı hastaya perkütan çapraz K teli ile tespit ve uzun bacak alçılama yapıldı. Ameliyat radyolüsen masada gerçekleştirildi. Redüksiyon aksiyel traksiyon yapılarak ve fleksiyon tipi kırıklarda gastroknemiusun distal parçayı posteriora çekmesini önlemek amacı ile diz altına yaklaşık $30^{\circ}$ açı oluşturacak şekilde yastık koyularak redüksi- 
Tablo 2: Hastaların kırık etiyolojileri ve diğer kırıkla ilişkileri veriler

\begin{tabular}{|c|c|c|c|c|c|}
\hline Yaş & Travma Şekli & Ek Hastalık & Sagittal def. & Koronal def. & ROM \\
\hline 7 & ADTK & yok & yok & yok & tam \\
\hline 8 & YD & yok & yok & yok & tam \\
\hline 6 & YD & yok & yok & yok & tam \\
\hline 4 & düşme & yok & yok & yok & tam \\
\hline 5 & $\mathrm{BD}$ & yok & yok & yok & tam \\
\hline 5 & FTR & SP & yok & yok & $30^{\circ}$ ekst. \\
\hline 5 & YD & yok & yok & yok & tam \\
\hline 5 & düşme & OI & yok & yok & tam \\
\hline 10 & YD & yok & yok & yok & tam \\
\hline 13 & düşme & OI & $5^{\circ}$ flek. & yok & $10^{\circ}$ ekst. \\
\hline 12 & ADTK & yok & yok & yok & tam \\
\hline 13 & AiTK & yok & $10^{\circ}$ flek. & $7^{\circ}$ varus & tam \\
\hline 11 & YD & yok & yok & yok & tam \\
\hline 12 & ADTK & yok & yok & yok & tam \\
\hline 7 & YD & yok & yok & yok & tam \\
\hline 8 & ADTK & yok & yok & yok & tam \\
\hline
\end{tabular}

ROM: eklem hareket açıkı̆ğı, ADTK: araç dışı trafik kazası, YD: yüksekten düşme, BD: bisikletten düşme, FTR: fizik tedavi, Ol: osteogenezis imperfecta,

AiTK: araç içi trafik kazası, flek.: fleksiyon, ekst.: ekstansiyon

yon sağlandı. K telleri kırık hattına ilerletildikten sonra skopi ile AP-Lat pozisyonlarda redüksiyon kontrol edildikten sonra $\mathrm{K}$ telleri proksimal fragmanın korteksinden geçecek şekilde ilerletildi. Hastaların hepsine medial ve lateralden birer adet çapraz $\mathrm{K}$ teli ile tespit yapıldı. Ortalama 10,6 (10-12) haftada tüm hastalarda kaynama sağlandı. Ortalama 82,9 (12-133) ay takip süreli hastalarda ameliyat sonrası değerlendirme amaçlı ayakta AP-Lat grafi çekildi; eklem hareket açıklığı ve uzunluk farkına bakıldı. İki hastada $1 \mathrm{~cm}$, iki hastada $2 \mathrm{~cm}$ ve bir hastada $3 \mathrm{~cm}$ ekstremite kısalığı saptandı. $3 \mathrm{~cm}$ boy kısalığı saptanan hastada aynı tarafta spastisiteye bağlı yüksekte kalça çıkığı mevcut idi. Topallama spastisitesi olan bir hasta ve $2 \mathrm{~cm}$ kısalığı olan iki hasta hariç diğer hastalarda tespit edilmedi. Eklem hareket açıklığı ölçümleri spastisitesi olan hastada $30^{\circ}$ ekstansiyon kaybı ve bir hastada $10^{\circ}$ ekstansiyon kaybı dışında diğer hastalarda tam idi. Ayakta çekilen grafilerde sagittal deformite $10^{\circ}$ ve $5^{\circ}$ fleksiyon pozisyonunda olmak üzere iki hastada saptandı. Koronal deformite olarak bir hastada $7^{\circ}$ varus deformitesi tespit edildi.

\section{TARTIŞMA}

Suprakondiler femur kırıkları AO/ASIF klasifikasyonuna göre 33-A grubunda yer alır. Genellikle uyluk anterior veya lateraline direkt çarpma veya yüksekten düşme sonucu oluşur. Fakat Smith ve ark.'ın belirttiği gibi patolojik kemiklerde düşük enerjili travmalar sonrasında kırık meydana gelebilir (4). Smith ve ark'ın çalışmasında 12 hastanın 4'ünü kırık riskini arttıran predispozan muskuloskletal sorunları olan hastalar oluşturmaktadır (4). Bizim de 16 hastalık çalışmamızda muskuloskletal sistem problemi olan 3 hasta mevcut idi [(osteogenesis imperfekta $n=2$, serebral palsi $(n=1)(2)$, serebral palsi (1)].

Nondeplase kırıklarda tedavi yöntemi basittir ve direkt alçılama tedavi edilir. Deplase suprakondiler kırıkların traksiyon ile tedavisinde adduktor ve gastroknemius kaslarının çekmesine bağlı olarak kırığın redüksiyonu sağlamak zordur $(2,6,7)$. Fakat 3 hafta traksiyonu takiben alçılama yaptığımız 4 hastada redüksiyon kaybı ve takiplerde bir problem ile karşılaşmadık. Deplase suprakondiler femur kırıkların cerrahi tedavisinde birkaç yöntem tanımlanmıştır. Perkütan 2 pin ile tespit ve alçılama en sık kullanılan yöntemdir. Eksternal fiksatör ile tedavide tanımlanmıştır, fakat pinlerin epifize zarar verme olasılığı vardır (4). Plak ile tespitte distal parça küçük olduğundan ve fizise zarar verme olasılığı olduğundan T plak kullanılır ve stabiliteyi devam ettirmek amacıyla alçı ile tedaviye devam edilir. Ama genellikle ilk tedavi seçeneği olarak kullanılmamıştır. Smith ve ark. kontroller sırasında redüksiyon kaybı olan bir hastaya en son operasyon olarak plak ile tespiti kullandığını bil- 
dirmişlerdir (4). Ayrıca Hoi Yan LISS plak ile tespiti vaka sunumu şeklinde yayınlamıştır (8).

Biz cerrahi kararı aldığımız hastalara perkütan uygulama ile distalden proksimale medial-lateralden 2 adet $\mathrm{K}$ teli ile tespit ve alçı uyguladık. Pin ile tespitte proksimalden distale doğru tespit de önerilmiştir, ancak medialde $\mathrm{K}$ tel'inin uygulanması sırasında femoral damar-sinir yapılarının hasar görme riski mevcuttur. Ayrıca distalden uygulanan yöntemde kondiller cilt altında rahatlıkla palpe edilebildiğinden teknik olarak daha kolaydır.

Pin girişleri ekstrakapsüler olarak geçilmelidir intrakapsüler geçişlerde dizde septik artrite yol açabilir (5). Birch ve ark. sinovyal birleşim yerini kadavra çalışması olarak göstermişler, medialde sinovyal yapışma lateral yapışma yerine göre daha distalde olduğunu tespit etmişler. Lateraldeki yapışma yerinin ekstrakapsüler yeri daha posteriordadır (9). Pine bağlı büyüme plağında yaralanma olabilir. Bu pin tipi (düz-yivli), pin boyutu, fizisten geçiş açısı ve penetrasyona bağlıdır (10). Pin epifizyel aksa ne kadar dik geçer ise etkilenme o kadar az olmasına rağmen pratik olarak genellikle 30 derece açı şeklinde uygulanır.

Biz vakalarımızda düz pin kullandık. Ayrıca uygu- lama kolaylığı olarak kondiller seviyesinden fizis hattından geçen bir yol uyguladık. Makela ve ark. kalıcı büyüme hasarının olması için distal femur fizinin en az $\% 7^{\prime}$ sinin hasarlanması gerektiği sonucuna varmışlar (11), Christopher ve ark'da kendi serisinde fizis hattından geçen pinin fizisin ancak \%1'ni etkilediğini saptamışlar (5). Pin genellikle 5 haftada kallus görüldükten sonra çıkarılır.

\section{SONUÇ}

Bizim serimizde pediatrik femur kırıkları içinde suprakondiler femur kırığı \%5,7 oranında bulundu. Düşük enerjili travmalar sonrası oluşan kırıklarda muskuloskletal hastalıklar sorgulanmalıdır. Nondeplase kırıkların tedavisi basit ve tedavi sonuçları memnun edicidir. Deplase kırıklarda traksiyon sonrası alçılama veya birkaç cerrahi metod kullanılmaktadır. Hastanede kalış süresinin kısa olması ve hasta morbiditesinin daha az olması nedeni ile cerrahi prosedür olarak perkütan pinleme ve uzun bacak alçılama uygulamayı öneriyoruz. Çocuklarda remodeling kapasitesinin yüksek olmasından dolayı konservatif veya cerrahi tedaviye karar vermek için geniş serili ve uzun takip süreli yayınlara ihtiyaç vardır.

\section{KAYNAKLAR}

1. Hubert M, Evrard H. Les fractures condylienes et supracondylienes du femur chez l'enfant et l'adolescent. Acta Orthop Belg 1982;48:749-56.

2. Kasser J. Femoral shaft fractures. In: Rockwood C, Wilkins K, Beaty J, eds. Fractures in children. Philadelphia: LippincottRaven; 1996:1224.

3. Rang M. Femoral shaft. In: Rang $M$, ed. Children's fractures. Philadelphia: Lippincott; 1983:277-9.

4. Smith NC, M.B., Parker D, and MCNicol D.Supracondylar Fractures of the Femur in Children. J Pediatr Orthop, Vol. 21, No. 5, 2001. 600-603.

5. Butcher CC, Hoffman EB.Supracondylar Fractures of the Femur in Children Closed Reduction and Percutaneous Pinning of Displaced Fractures. J Pediatr Orthop 2005;25:145-148.

6. Canale $S$, Tolo V. Fractured femurs in children J Bone Joint Surg (Am) 1995;77:295-315.

7. Tolo V. Fractures and dislocations about the knee. In: Swiontkowski M, Green N, eds. Skeletal trauma in children. St. Louis: WB Saunders; 1998:431-6.

8. Lam HY, Lo CK, Cheung KY. The use of tibial Less Invasive Stabilization System (LISS) plate [AO-ASIF] for the treatment of paediatric supracondylar fracture of femur: a case report. J Orthop Surg Res 2010, 5:10.

9. Birch JG, Herring JA, Wenger DR. Surgical anatomy of selected physes. J Pediatr Orthop. 1984;4:224-231.

10. Petersen HA. Partial growth plate arrest and its treatment. J Pediatr Orthop. 1984;4:246-258.

11. Makela EA, Vainionpa $S$, Vihtonen $K$, et al. The effect of trauma to the lower femoral epiphyseal plate. J Bone Joint Surg. 1988;70-B:187-191. 